\section{Diálogos terapêuticos sobre suicídio e o valor da vida no Centro de Atenção Psicossocial}

\section{Liporaci, Bruno de Paula Checchia}

Mestrando, Especialista em Direitos Humanos, Bacharel em Direito, Graduando em Serviço Social). EERP/ USP/ UFTM. E-mail: bliporaci@yahoo.com.br

\section{Magrini, Daniel Fernando}

Prof. Mestre. Centro Universitário UNIFAFIBE. E-mail: magrini.df@gmail.com

CAAE: 00399218.1.0000.5387

PALAVRAS-CHAVE: Suicídio. Saúde mental. Intervenção. Cuidados para prolongar a vida. Psicoeducação.

Introdução: O suicídio é caracterizado como um fenômeno atual e multicausal, decorrentes de aspectos sociais, culturais, psicológicos, biológicos, religiosos ou outros [1]. A Organização Mundial da Saúde afirma que pessoas atendidas na saúde mental tentam suicídio até $80 \%$ mais que as demais, e se somados, os transtornos de humor, de personalidade, esquizofrenia, uso e abuso de drogas, são suas principais causas [2]. Método: encontros semanais em instituição de saúde mental, com pacientes que tentaram suicídio, inicialmente com tema livre, depois os participantes escolheram assuntos relacionados ao suicídio e a valorização da vida. Entre os principais interesses e dúvidas estavam "Por que o paciente se machuca", "Minha família tem influência para que eu tente me machucar", "suicídio é hereditário?", “Qual o meu diagnóstico e como ele afeta para o suicídio?". Foram elaborados acordos e de não abordagem dos meios contra a vida. No grupo fechado utilizou-se as técnicas do Open Dialogue [3] de intervenção da crise e sequências das atividades. Discussão: na sociedade há o senso comum que encara o suicídio comparativo às doenças físicas e decorrente de causas orgânicas, destituindo-o dos elementos subjetivos, sociais, psíquicos, espirituais e financeiros. Sem a compreensão da totalidade do que levou a pessoa se suicidar, tais como as citadas anteriormente, sucumbe em condições desfavoráveis para a prevenção do risco suicida. No caso dos Centros de Atenção Psicossociais estas realidades são resgatadas e favorecem que não sejam feitas novas tentativas contra a própria vida [4]. Grupos terapêuticos nestas instituições de saúde criam laços de valorização da vida e entendimento sobre o suicídio. Resultado e Conclusões: Reflexão sobre vivências sui generis sobre a vida, sobre o hábito da automutilação, heteroagressividade, alucinações audiovisuais e a comparação entre o diagnóstico e sua influência na prática do suicídio. Manterse grupos de psicoeducação, operativos ou de outras ordens na área da saúde mental favorece a reflexão sobre o suicídio e a vida e pode favorecer o alo e autovalor [5].

\section{REFERÊNCIAS}

[1] E. KALINA, As cerimônias da destruição. Rio Janeiro (RJ): Francisco Alves (1981).

[2] World Health Organization (WHO). Preventing suicide A global imperative. (2014). Disponível em http://apps.who.int/iris/bitstream/10665/131056/1/97892415 64779 eng.pdf?ua $=1 \& u a=1$ Acesso em 11 set. 2018.

[3] J. SEIKKULA; B. ALAKARE, B.; J. AALTONEN, Open dialogue in psychosis I: an introduction and case illustration. Journal of constructivist psychology, Washington, DC. v. 14, n. 4, p. 247-265 (2001).

[4] A. COSTA-ROSA, C. A. LUZIO, S. YASUI, Atenção psicossocial: rumo a um novo paradigma na Saúde Mental Coleti va. In: Amarante P. Archivos de saúde mental e atenção psicossocial. Rio de Janeiro: Nau;. p.13-44 (2003).

[5] W. T. CHIEN, Effectiveness of Psychoeducation and Mutual Support Group Program for Family Caregivers of Chinese People with Schizophrenia. The Open Nursing Journal, 2, 28-39 (2008). 